Türk Dili Araştırmaları Yılığı-BELLETEN / Yearbook of Turkic Studies BELLETEN

Yıl/Year: 2018, Cilt/Volume: 66, Sayı/Issue: 1 - ISSN: 0564-5050/e-ISSN: 2651-5113 Ankara, TÜRKIYE/TURKEY DOI Numarası/DOI Number: 10.32925/tday.2018.6

\title{
ANLAMDAŞ ADDEDİLEN BİRKAÇ KELIMMENIN MANA FARKLARI HAKKINDA NOTLAR
}

Yasin YAYLA*

$\ddot{O ̈ z e t}$

Anlamdaş kelimelerin gerek varlı̆̆ gerekse mahiyeti ile ilgili dil bilimciler çeşitli araştırmalar ortaya koymuşlardır. Bu çalı̧̧mada bu tür kelimelerde zamanla meydana gelen mana bulanikliğ v veya mana kaybı ile ilgili birkaç örnek vererek konuya katkı sağlamaya gayret edilecektir. "Dilde sadeleşme" gibi bazı sebepler birçok kelimeye sirt dönülmesine sebep olmuş; bu durum önce yazı dilinde, daha sonra zamanla konuşma dilinde kelimelerin unutulması veya manalarının bulanılkaşarak birbirleriyle karışması neticesini doğurmuştur. Bu durumdan anlamdaş kelimeler de nasibini almış, bazı kelimelerin manalarında eksilme ve değişme olması anlamdaş kelimeler arasindaki mana farklarının tamamen yok olmasına sebep olmuştur. Bazı anlamdaş kelimeler hem konuşma dilinden hem de yazı dilinden tamamen çıkmış, sadece lügatlerin bir köşesinde unutulmayı bekler hâle gelmiştir. Bu çalışmada eş anlaml sayllan ve mana farklarl unutulmuş ya da unutulmaya yüz tutmus ikazihtar, fiil-amel, defetmek-refetmek, cem-haşir kelimeleri arasindaki mana farkları incelenmiştir. Kelimelerin önce müteradif Türkçe sözlüklerdeki manaları verilmiş, daha sonra da farklart izah edilmiştir.

Anahtar Kelimeler: Anlamdaş, dil bilimi, Türkiye Türkçesi, sözlük, mana farkl.

\section{Notes on the Meaning Differences About a Few Words Considered as Synonym}

\begin{abstract}
Various studies have been carried out by linguists on the existence and characteristics of synonymy. This study, will try to contribute to the topic by giving examples on the loss of meaning which appears in such words. Some reasons, such as "simplification of language", have resulted in many words becoming archaisms. Hence, both in written and later in spoken language words were disused or their
\end{abstract}

* Doktor, Surbistan Novi Pazar Devlet Üniversitesi, yyasinyayla@gmail.com, https://orcid.org/00000001-5726-884X 
meanings became ambiguous and confused with each other. Because of loss or change of meaning, nuances of synonyms have completely disappeared. Some words have completely disappeared both in the spoken and written language. Those words await to be disused in dictionaries. The semantic differences between the words ikazihtar, fiil-amel, defetmek-refetmek, cem-haşir have been examined. These words are considered synonyms and their semantic differences have been forgotten or are about to be forgotten.

Keywords: Synonymy, linguistics, Modern Turkish, dictionary, sensenuance.

\section{Giriş}

Anlamdaş ya da eş anlamlı kelime Arapça "müteradif", Fransızca "synonyme” kelimelerinin karşılı̆ğ olarak kullanılmaktadır.

Anlamdaşlık ya da eş anlamlılık dil bilimciler tarafından tartışılagelen bir konudur. Birçok dil bilimci anlamdaş kelimeler arasında mana farklılıkları olduğunu savunmaktadır. Aksan'a (2003) göre hiçbir dilde birbirinin tam aynı anlama gelebilecek kelimelerin olması mümkün değildir (s. 191). Tekin’e (1997) göre yabancı asıllı karşılığı ile anlamdaş sanılan birçok kelime gerçekte öyle değildir. Dilin canlı söz hazinesinde gerçekten anlamdaş kelimeler yoktur. Anlamdaş oldukları zannedilen kelimeler arasında daima ince bir anlam farkı vardır; bu yoksa bile kullanış farkı bulunur (s. 116).

Bazı dil bilimcilere göre anlamdaş sayılan kelimelerden Arapça ve Farsça olanlarının bazıları zamanla kullanıştan düşecektir. Lisan yerine dil, evvel yerine önce, sene yerine yıl, sıhhat yerine sağllk, lazım yerine gerek, endişe yerine kaygl kullanılacaktır. 1968'den beri bu kelime ikilileri bir arada yaşamaktadır. Sanıldığı gibi bu kelimeler anlamdaş olsaydı kelime ikililerinden biri kullanıştan düşerdi (Sulak, 2016, s. 39). Dilde en az çaba ilkesi vardır. Aynı anlama gelen kelimeler birlikte aynı dilde yaşayamazlar. Eğer yaşıyor gibi görünüyorsa mutlaka ince de olsa bir fark vardır (Erkman, 2008, s. 200).

Anlamdaşlik mevzusu her dilde zaten çözülmesi gereken bir mesele iken Türkçede, dilde sadeleşme neticesinde, anlamdaşlik meselesi ile birlikte bir de benzer manalı kelimelerin sözlüklerde bulunsalar bile konuşma ve yazı dilindeki işlerliklerini yitirmeleri ya da farklarının fark edilemez hâle gelmesi meselesi ortaya ç1kmıştır.

Dili sadeleştirelim denilirken kelimeler arasındaki mana farkları görmezden gelinerek birbirinden farklı mefhumların tek bir kelime ile karşılanması garabetiyle karşı karşıya kalınmıştır. Mesela ikaz ve ihtar diye birbirine benzeyen fakat farkları olan iki kelimenin bugün ikisinin de bir 
kısmını karşılayan; fakat perdenin öteki tarafından bakınca ikisinin de bir kısmını karşılayamayan uyarı kelimesi ile ifade edilir ya da ifade edilemez hâle geldiği görülmektedir. Müellif, musannif, muharrir gibi üç farklı sahada üç farklı iş yapan kişiye ad olan kelimeler bugün sadece yazar diye ifade edilmeye çalışılmaktadır.

Akla "İyi de bu kelimeler madde başı olarak sözlükte var, dilden atılmadı ki!" diye bir itiraz gelebilir; fakat bir kelimenin sözlükte var olması o kelimenin dilde yaşadığ Öğrencilerin ders kitabında olmayan, sokaktaki insanın dilinde yaşamayan, zihinde farkı fark edilemeyen hiçbir kelime bizim değildir.

Bu kelimeleri kullanmaya çalışan insanların çarptıkları ilk duvar, "Bunlar eski kelimeler!" engelidir. Kelimenin eskisi ve yenisi elbisenin eskisi ile yenisi gibi mi yoksa arkadaşın eskisi ile yenisi gibi mi algılanmalı? Kelimeler; "Öz Türkçe", "Arapça", "Farsça" vs. diye ayrılmalı mı, yoksa öbür dillerden alınan kelimeler için "Bunları asırlardır kullanıyoruz, mana dokumamızdan geçmiş, sağlamca örülmüşs." deyip "Artık Türkçedir." mi denmeli? Büyük ünlü uyumuna uymayan "kitap" büyük ünlü uyumuna uyan "silgi”den daha mı az Türkçedir ya da ikisi de öz be öz Türkçe midir?

Bu kısır tartışmanın bir sonu olmadığı herkesin malumudur. Dilde asırlardır var olan bir kelimeye "Bu kelime, şu dilden gelmiştir." deyip Türkçe karş1lık uydurmaya çalışmak, dilde fakirleşmeye doğru bir gidiştir. Dil, canlı bir varlıktır ve beraberinde kültürü de taşır. Dolayısıyla dışarıdan müdahalelerle dili değiştirmeye çalışmak, dilin kimyasını bozmakla birlikte insanların ve cemiyetlerin düşünce dünyasında da tamiri mümkün olmayan yaralar açabilir.

Anlamdaş kelimelerin mana ve kullanılış farkları unutulmaya başlandığ1 için bu çalışmada birincisi işlerliğini koruyan fakat ikincisi işlerliğini yitirmiş dört tane kelime ikilisinin arasındaki mana farkları incelenmiştir. Kelime ikilileri şunlardır: ikaz-ihtar, fiil-amel, defetmek-refetmek, cem-haşir.

\section{Kelimeler}

ikaz - ihtar: Müteradif Türkçe sözlüklerde ikazın manası şu şekildedir: '1. Uyarma, uyarı, dikkat çekme, ihtar, tembih. 2. Uyandırma' (Türk Dil Kurumu, 2011, s. 945), 'Uyandırma, uyarma, dikkatini çekme, gözünü açma' (Ayverdi, 2005, s. 1372), 'uyandırma, uyarma' (Nişanyan, 2009, s. 259). Ihtarın manas1 ise şu şekildedir: '1. Uyarma, dikkat çekme, uyarı. 2. Birine bir şeyi hatırlatma' (Türk Dil Kurumu, 2011, s. 942), '1. Hatırlatma. 2. Dikkat çekme, uyarma. 3. Bir görevliye görevini daha iyi yapması, daha dikkatli davranması gerektiğini bildiren disiplin cezası, uyarı.' (Ayverdi, 2005, s. 1364), 'uyarma' (Nişanyan, 2009, s. 258). 
Yukarıda zikredilen manalardan da görüleceği üzere iki kelime de 'uyarı' manasında birleşip kavramlar birbirine girmiştir.

Kelimelerin manalarını teker teker incelersek:

ikaz: < Ar. $\bar{i} k \bar{a} z ;<-k-z$ 'uyanık olmak, uyanmak' (el-Fîrûzâbâdî, 1268, s. 2, 540; Atay, 1965, s. 348). Yine Arapça $y-k$ - $z$ kökünden türeyen ve Türkçede de kullanılan teyakkuz kelimesinin manası da Türkçe Sözlük'te 'uyanıklık' (Türk Dil Kurumu, 2011, s. 945) şeklinde manalandırılmıştır.

ihtar: < Ar. ihțār 'hatırına getirmek, hatırlatmak' (Atay, 1964, C 1, s. 473) $<$ h-ț-r 'hatırına gelmek, zihnine doğmak' (Atay, 1964, C 1, s. 472). Yine ihtar ile aynı kökten türeyen muhtıra kelimesi 'herhangi bir şeyi hatırlatmak hedefiyle yazılan yazı' (Türk Dil Kurumu, 2011, s. 1417) demektir.

Görüleceği üzere ikaz kelimesi ‘uyanık olmak' ile ilgili iken ihtar kelimesi 'hatırlatmak' ile ilgilidir.

Kelimelerin günlük hayatta kullanılma farklarını düşündüğümüzde:

Araçların ikaz lambaları vardır ama ihtar lambaları yoktur; çünkü aracın ikaz lambası durulmaması gereken bir yerde durulması gibi hâllerde öteki insanları "uyanıklığa" sevk etmek için kullanılır.

Güreş müsabakasında hakem ikaz vermez ihtar verir; çünkü müsabaka öncesinde kuralları söylemiştir ve ihtar vererek daha önce söylediği kuralları hatırlatır.

Askeriyede "Prize parmağını sokma!" yazısı bugün uyarı olarak geçse de bir ikazdır; yani "Uyanık ol, prize parmağını sokarsan elektrik çarpar." demek istemektedir.

Görüleceği üzere ikaz, uyanık olma manasında bir uyarı iken ihtar hatırlatma manasında bir uyarıdır. İki farklı durumdan bahseden bu kelimeleri bugün sadece uyarı kelimesi ile karşılamaya çalışmak zihindeki iki farklı mefhumu teke indirerek düşünmeyi engellemek demektir.

fiil - amel: Müteradif Türkçe sözlüklerde fiil 'davranış' (Türk Dil Kurumu, 2011, s. 700), 'Olup gerçekleşmiş iş, yapılıp gerçekleşmiş hareket veya davranış, kasıtlı kasitsız her türlü iş, eylem, amel' (Ayverdi, 2005, s. 959), 'edim, eylem' (Nişanyan, 2009, s. 187); amel ise 'yapılan iş, edim, fiil' (Türk Dil Kurumu, 2011, s. 88), '1. Bir maksatla yapılan iş, eylem, fiil. 2. Dinî emirleri yerine getirmek için yapılan iş, fiil, hareket' (Ayverdi, 2005, s. 128), 'iş, işlem, eylem' (Nişanyan, 2009, s. 21) olarak tanımlanmaktadır.

Kelimelerin manaların teker teker incelersek: 
fiil: < Ar. fi'l< $f_{-}$'- $l$ 'yapmak, etmek' (Atay, 1965 s. 254), fi 'l 'Hareket-i insandan ibarettir. Alâ kavl ahire müessir ve müteaddi olan her amelden kinayedir. Türkîde iş Fârsîde kâr denir.' (el-Fîrûzâbâdî, 1268, C 3, s. 297).

amel: < Ar. 'amal < '-m-l' 'iş yapmak, işlemek, çalışmak, gayret sarfetmek; sanatla uğraşmak' (Atay, 1981, C 3, s. 487), 'bir şeyde eser meydana getirmek' (Askerî, 2009, s. 184). Yine '-m-l kökünden türeyen a 'malahu 'işçi, memur vs. olarak çalıştırmak, alet vs.'yi işte kullanmak, fikir ile iş görmek' (Atay, 1964: 3, 488), ista 'mala 'fikrini çalıştırmak, tuğla, kerpiç vs.den bina yapmak' (Atay, 1981, s. 3. c., 488), ustu 'mila 'devlet işlerinde görevlendirmek' (Atay, 1981, C 3, s. 488), 'amala 'canlıların kasten yaptıkları iş' (Atay, 1981, C 3, s.488), 'âmil 'işçi, sanatkâr, kalfa, usta, işte vekil olan, usta başı, vergi ve zekât toplayan memur' (Atay, 1981, C 3, s. 488).

Kamus Tercemesi'nde fiil ile amelin farkı şöyle izah edilmektedir: "Amal, fi'l ile müradiftir ve inde 'l-ba'z fiilden ehastır; zira fi'l bi-kast ve bi-gayr-i kast olana şamildir. Onun için bazı hayvanata nispet olunur ve amal bi-kast olana mahsustur. İbl-i avâmilden gayrı hayvanata nispet olunmamıştır, olduğu mecazdır." (el-Fîrûzâbâdî, 1268, C 3, s. 297).

Yine fiil ile amelin farkından olmak üzere: "Amal fi 'lden daha özeldir; çünkü 'amal kasdî [iradî] bir fiil olup hayvanlara ve cansızlara nispet edilemez.” (Bursevî, 2011, s. 313).

Fiil ve amel fark1 için başka örnekler: "Abdestin iptidasında besmeleyi unutsa da esnasında söylese sünnet hasıl olmaz. Yemek yemek gibi değildir. Abdest amel-i vâhiddir. Yemekte ise her lokma bir fiildir. Esnâ-yı eklde dahi besmele okunsa hem mazi hem de baki için sünnet hasıl olmuş olur." (Kāmûs-ı Fârsî, 1, 86).

"Mesela hüsn-i hatta veya musiki ve raksta meleke hasıl edenler hiç düşünmeksizin güzelce ve süratle icrâ-yı amel eylerler." (Kāmûs-ı Fârsî, 21, 41). "... midenin âdetten ziyade fi'l-i hazmı icra etmesi ..." (Kāmûs-ı Fârsî, $21,42)$

Yukarıdaki bilgileri özetlemek gerekirse:

1. Amel hedef dâhilinde maksatlı bir iş yapmakken fiil işin umumi adıdır.

2. Amel müzik icrası gibi öğrenilip daha sonra refleksf hâline gelen işler, davranışlar için kullanılırken; fiil sonradan öğrenilmeyen, midenin yemekleri hazmetmesi gibi doğuştan refleksif olarak yapılan işlerdir.

Amel hedef dâhilinde yapılan iş olduğu için Türkçe Sözlük'te fiilin karşılığına verilen 'davranış' (Türk Dil Kurumu, 2011, s. 700) amelin karşıllı̆ıında, amelin karşılığında verilen 'işs' (Türk Dil Kurumu, 2011 s. 88) ise fiilin karşıllı̆ında olmalıdır. 
defetmek - refetmek: Müteradif Türkçe sözlüklerde defetmek ' 1 . Kovmak. 2. Savmak, savuşturmak.' (Türk Dil Kurumu, 2011, s. 482), '1. Savmak, uzaklaştırmak, kovmak. 2. Gidermek, ortadan kaldırmak, yok etmek, bertaraf etmek.' (Ayverdi, 2005, s. 645), 'tepme, kovma, geri verme' (Nişanyan, 2009, s. 122) manasinda iken refetmek '1. Yukarı kaldırmak. 2. Ortadan kaldırmak, gidermek' (Türk Dil Kurumu, 2011, s. 1648), '1. Yukarı kaldırmak, yükseltmek. 2. Yüceltmek. 3. Ortadan kaldırmak, feshetmek, lağvetmek, hükümsüz bırakmak. 4. Kaldırmak, yok etmek, gidermek.' (Ayverdi, 2005, s. 2565), 'kaldırma' (Nişanyan, 2009, s. 516) manalarıyla kayıtlıdır.

Görüleceği üzere iki kelimede de bir "reddetme, kabul etmeme" manas1 bulunmaktadır.

İki kelimenin de yardımcı fiil kısmı Türkçe "et-” fiili olduğu için sadece Arapçadan gelen kısımları incelenecektir:

def: < Ar. $d a f^{\prime}<d-f$-' 'itmek, dürtmek, geriye atmak, püskürtmek, öte kakmak, savmak, uzaklaştırmak, reddetmek, kakıvermek.' (Atay, 1968, C 2, s. 535). Yine aynı kökten türeyen daffa 'a 'kuvvet kullanarak savmak, bertaraf etmek, uzaklaştırmak' (Atay, 1968, C 2, s. 535) manasında kullanılmaktadır.

ref: < Ar. raf' < r-f-' 'suçluyu mahkemeye vermek, sevk etmek.' (Atay, 1968, C 2, s. 768). Yine aynı kökten türeyen rafa 'ahu 'kaldırmak, yükseltmek, düşmanı harp meydanından sürüp çıkarmak' (Atay, 1968, C 2, s. 768) manasında kullanılmaktadır.

Bursevî (2011) iki kelimenin farkını şöyle izah ediyor: "Daf" savma, olay öncesi için kullanılır; raf " uzaklaştırma, olay sonrası için kullanılır." (s. 368).

İki kelimenin ve kelimelerle aynı kökten türeyen kelimelerin kullanılış farklarından olmak üzere:

Defihacet 'küçük veya büyük abdest bozmak' (Türk Dil Kurumu, 2011, s. 482). Anlaşılacağı üzere defihacette vücuda kabul edilmeyen şeyler dişarıya atılmaktadır; yani vücuda alınmamaktadır.

Birine def ol dediğimiz zaman onunla konuşmak istememekte, başımızdan savmakta; yani zihin dünyamıza kabul etmemekteyiz.

Ref ile aynı kökten türeyen terfi 'Derece, makam bakımından yükselme' (Türk Dil Kurumu, 2011, s. 1959) manasına gelmektedir. Terfi alan kişi bir kademeden çıkarak başka bir kademeye geçmekte yani bir kademeden dışarı çıkmaktadır.

Bir kanun ref edildiği zaman yürürlükten kaldırılmış olur; yani içeriden dişarı atılmış olur. 
Bilgilerden anlaşılacağı üzere def etmek 'dışarıdakini içeri almamak' manasında iken ref etmek 'içeridekini dışarı atmak' manasındadır.

cem - haşir: Müteradif Türkçe sözlüklerde cem 'toplama, bir araya getirme' (Türk Dil Kurumu, 2005, s. 356), '1. Toplama, toplanma, bir araya gelme, getirilme. 2. Topluluk, cemiyet, meclis' (Ayverdi, 2005, s. 467), 'toplama, toplanma, topluluk' (Nişanyan, 2009, s. 90) şeklinde tanımlanırken haşir 'toplanma, bir araya gelme' (Türk Dil Kurumu, 2011, s. 855), '1. Toplama, bir araya getirme. 2. Cenabıhakk' nn kıyamet gününde, dünya hayatında işlediklerinin hesabını sormak üzere ölüleri diriltip bir araya toplaması. 3. Ölülerin diriltilip bir araya toplandığı zaman, kıyamet' (Ayverdi, 2005, s. 1200-1201), '1. Toplanma, kalabalık etme. 2. Mahşer, kıyamet' (Nişanyan, 2009, s. 231) şeklinde tanımlanmıştır.

Kelimelerin manalarını teker teker incelersek:

cem: < Ar. cam '< c-m- ' 'kavim toplanmak, birikmek' (Atay, 1964, C 1, s. 290), 'dağınık nesneyi biriktirmek' (el-Fîrûzâbâdî, 1268, C 2, s. 559). Yine aynı kökten türeyen istacma 'a 'her taraftan gelip toplanmak' (Atay, 1964, C 1, s. 291) cāmi ' 'cami, mescit, bir araya getiren, toplayan', macma' 'urum, toplant1 yeri, salonu, istişare meclisi' (Atay, 1964, C 1, s. 292), muctama ' 'toplant1 yeri, salonu' (Atay, 1964: 1, 293), al-macmū' 'Şuradan buradan birikmiş nesneye denir.' (el-Fîrûzâbâdî, 1268, C 2, s. 559), al-cimā' 'büyük tencere' (el-Fîrûzâbâdî, 1268, C 2, s. 559).

haşir: < Ar. haş̧r < h-ş-r 'Toplamak, bir araya getirmek, keskinletmek, inceltmek, birini sıkıştırmak, darlatmak' (Atay, 1964, C 1, s. 380). Yine aynı kökten türeyen haşşara 'Basarak birbirine katmak', yavmu 'l-ḩaşri 'İnsanların öldükten sonra kabirden kalkıp toplanacağı gün, toplanma günü' (Atay, 1964, C 1, s. 380), haşarat 'tahılların, tanelerin iç kabuğu' (Atay, 1964, C 1, s. 381), haşarat 'böcek, haşere, tahta kurusu, eza veren küçük canavarlar, akrep, fare' (Atay, 1964, C 1, s. 381), maḩ̧̧ar 'insanların toplandığ yer' (Atay, 1964, C 1, s. 381).

Bursevî (2011) iki kelimenin farkını şöyle izah ediyor: "Haşrr sevk ve mecburiyet manasında toplamadır. cam'de ise bu mana gözetilmez." (s. 353).

İki kelimenin farklarından olmak üzere:

1. Cuma Müslümanların camide toplanma günüdür. Müslümanlar ezan ile davet edilir ve farklı farklı yerlerden, dağınık hâlde iken bir araya, kapalı bir mekâna toplanırlar.

2. Arapça $h$-ş-r kökünden türeyen mahşer ölülerin kendi iradeleri dışında mezarlarından kalkıp toplanacakları meydandır. 
3. $C$-m- ' kökünden türeyen mecmua farklı farklı insanların farklı farklı yazılarının iki kapak arasında toplandığı kitapçıktır.

4. Haşere böcek demektir ve özellikle tahtakurusu, hamam böceği başta olmak üzere insanlara rahatsızlık veren böcekler gece yuvalarından dışarı çıkarlar.

Haşir ve cem kelimeleri ile aynı kökten türeyen kelimelerin manalarını ve günlük hayattaki kullanılma alanlarını düşününce iki kelimenin manası şöyle olmal1:

Haşir 'kapalı bir alandan zorla açık bir alanda toplama', cem 'dağınık hâlde dışarıda bulunanları zorlama olmaksızın kapalı bir alanda toplama'.

\section{Sonuç ve tavsiyeler}

Çalışmaya konu olan kelime ikilileri şunlardır: ikaz-ihtar, fiil-amel, defetmek-refetmek, cem-haşir. Kelimelerin incelenmesiyle mana farklar1 babında şu neticelere varılmıştır:

İkaz önceden söylenmemiş, uyanık olma manasında bir uyarı iken ihtar daha önceden bildirilmiş olan bir şeyi hatırlatma manasında bir uyarıdır. Günümüzde ihtar kelimesi işlerliğini yitirmiş neredeyse sadece güreş müsabakalarında kullanılır olmuştur.

Fiil deve hariç bütün hayvanların hareketleri için kullanılabilirken aynı zamanda yapılan işlerin genel adıdır; amel ise sadece insan davranışları için kullanılabilir ve bir hedef dâhilinde yapılan iştir yani davranıştır. Günümüzde amel kelimesi sadece dinî bir terim olarak kullanılmaktadır.

Defetmek dışarıdakini içeriye kabul etmeme manasında bir ret iken refetmek içeridekini dışarı atmak manasında bir rettir. Günümüzde refetmek konuşma ve yazı dilinde işlerliğini tamamen yitirmiş hâldedir.

Cem dağınık olanların zorlama olmadan kapalı bir alanda toplanması iken haşir zorlayarak açık alanda toplamadır. Günümüzde haşir kelimesi dinî bir terim olarak var olmakla birlikte neredeyse işlerliğini tamamen yitirmiştir.

TÖMER'in (Türkçe Öğretme Merkezi) yaptığı bir araştırmaya göre Amerika'da ortaöğretim ders kitaplarında 70.400, Almanya ve Japonya'da 44.224, İtalyan okullarında 31.762, Fransa'da 30.193, Suudi Arabistan okullarında 13.579 kelime ve terim kullanılırken Türkiye' deki ders kitaplarında yalnızca 7.260 kelime ve terim kullanılmaktadır (Sulak, 2016, s. 45).

Türkçeden "bu eski, bu yabancı, bu Arapça, bu Farsça vb." bahanelerle kelimeleri atmak yerine yüzyıllar boyunca kullandığımız, artık her şeyiyle bizim olmuş bütün kelimelerimize sahip çıkarak kelime hazinemizi zenginleştirmeliyiz. $\mathrm{Bu}$ kelime hazinesini zenginleştirme mevzusunda 
anlamdaş kelimeler arasındaki mana farklarını belirlemenin, örneklemenin ve ders kitaplarında da mana farklarını gösterici şekilde kullanmanın muhakkak ki büyük bir katkısı olacaktır.

Anlamdaş kelimelerin mana farkları bilinir ve bu kelimeler buna göre kullanılırsa daha geniş düşünebilen, konuşurken kelime aramaya çalışmayan, konuşma becerilerinin yanında yazma becerileri de daha üst seviyede olan gençler yetişeceği muhakkaktır. Bu mana farklarını ortaya çıkarmak ve ders kitaplarına eklemek de -hak verileceği gibi- Türkçe eğitimi ile uğraşanların işidir.

\section{Kaynaklar}

Aksan, D. (2003). Her Yönüyle Dil Ana Çizgileriyle Dilbilim. Ankara: Türk Dil Kurumu. el-Askerî, E. H. (2009). Arab Dili'nde ve Kur'an'da Farklar Sözlüğü el-Furûq fi'l-Luğa. İstanbul: İşaret.

Atay, H., Atay, İ., Atay, M. (1964-1981). Arapça Türkçe Büyük Lûgat. Ankara: Bayrak.

Atay, H., Atay, İ., Atay, M. (1965). Telaffuzlu Yeni Arapça-Türkçe Sözlük. Ankara: Medeniyet.

Ayverdi, İ. (2005). Misalli Büyük Türkçe Sözlük - Kubbealtı Lugati. İstanbul: Kubbealtı.

Bursevî, İ. H. (2011). Kelimeler Arasındaki Farklar Kitâbu'l-Furûq. İstanbul: İşaret.

Akerson, F. E. (2008). Türkçe Örneklerle Dile Genel Bir Bakış. İstanbul: Multilingual.

el-Fîrûzâbâdî, M. (1268-1272). el-Okyânûsu'l-Basît fî Tercemeti'l-Kámûsi'l-Muhît. İstanbul: Matba'a-y1 Bahriyye.

Sulak, S. G. (2016). Anlamdaş Kelimelerde Anlam ve Kullanış Farkları. Ankara: Gece.

Kāmûs-ı Fârsî. Ankara: Türk Dil Kurumu Kütüphanesi Etüt 80/1.

Nişanyan, S. (2009). Sözlerin Soyağacı Çağdaş Türkçenin Etimolojik Sözlüğü. İstanbul: Everest.

Tekin, T. (1997). Türkoloji Eleştirileri. Ankara: Simurg.

Türk Dil Kurumu (2011). Türkçe Sözlük. Ankara: Türk Dil Kurumu. 


\section{NOTES ON THE MEANING DIFFERENCES ABOUT A FEW WORDS CONSIDERED AS SYNONYM}

\section{Extanded abstract}

\section{Introduction}

Synonym is used as equivalent of "müteradif" in Arabic and "synonyme" in French.

Synonymy is a topic discussed by linguists. Many linguists argue that there are meaning differences between synonyms. According to Aksan (2003), it is not possible to have exactly same meanings words in any language (s. 191).

According to Tekin (1997) many words which are considered synonym with foreign counterparts exactly are not. There are no exactly synonyms in the vocabulary of language. There is always a nuance between words considered as synonym (s. 116).

According to some linguists some of the Arabic and Persian words considered as synonym will be discarded in progress of time.

Dil instead of lisan, önce instead of evvel, yıl instead of sene, săglık instead of sihhat, gerek instead of lazım, kaygl will be used instead of endişe. These word pairs have been living together since 1968. If these words were synonym as thought, one of these word pairs would discard (Sulak, 2016, s. 39).

There is least-effort principle in language. Words with the same meaning cannot live together in the same language. If it seems to be living in the language, there is a meaning difference (Erkman, 2008, s. 200).

While the synonymy is an issue that must be solved in every language, in addition to this issue, the problem of the loss of differences of similar meaning words has emerged in Turkish.

This study will try to contribute to the topic by giving examples on the loss of meaning, which appears in such words. Some reasons, such as "simplification of language", have resulted in many words becoming archaisms. Hence, both in written and later in spoken language, words were disused or their meanings became ambiguous and confused with each other. Because of loss or change of meaning, nuances of synonyms have completely disappeared. Some words have completely disappeared both in the spoken and written language. Those words await to be disused in dictionaries. The semantic differences between the words ikaz-ihtar, fiil-amel, defetmek-refetmek, cem-haşir have been examined. These words are considered synonyms and their semantic differences have been forgotten or are about to be forgotten. 


\section{Discussion and conclusion}

The word pairs that are the subject of the study are: ikaz-ihtar, fiil-amel, defetmek-refetmek, cem-haşir.

As a result of analyzing of the words the following conclusions are reached:

Íkaz is a warning about being awake and this warning has not been mentioned before. Ihtar is a reminder of something that has already been announced. Today the word ihtar has lost its function. It has almost exclusively been used in wrestling competitions.

Fiil can be used for the movements of all animals except the camel and also it is the general name of actions. Amel can be used exclusively for human behavior and it is a work with certain aim; in other words - behavior. Today the word amel has been used only as an Islamic term.

Defetmek is a refusal that does not accept the outside thing but refetmek is a refusal that throw the inside thing to outside. Today, refetmek has completely lost its function in both, colloquial and literary language.

Cem is a collection of dispersed ones without forcing but haşir is a collection in open field with forcing. Today the word haşir has been used only as an Islamic term.

According to a research by TÖMER (Turkish Teaching Center), 70.400 words and terms in high school text books in America, 44.224 words in Germany and Japan, 31.762 in Italy, 30.193 in France, 13.579 in Saudi Arabia were used; but 7.260 words and terms were used in Turkey (Sulak, 2016, s. 45).

We should not discard the words in Turkish language with excuses like "this old, this foreign, this Arabic, this Persian etc.". We must enrich our vocabulary with words that we have been using for centuries. It is very important to determine the differences between synonym words and to use them in textbooks.

The meaning differences between synonym words should be known and these words should be used in this way. If we can do that, it is clear that we can raise young people who can think more broadly, who do not try to search for words while talking, and who are capable of writing skills as well as speaking skills. To reveal these meaning differences and to add them to the textbooks is the work of people working on Turkish education. 
